\title{
Legal Use of Marijuana: Will Scientific Evidence Overwhelm Self-Perceived High Feeling?
}

Johnson S. Leonard, Ph.D.; Mary K. Pathak, M.Sc.

\section{SUMMARY}

With the legalization of recreational marijuana, the concerns about its potential negative impact on abusers' cognitive and mental health have not been being discussed thoroughly. Driven by commercial interests, many marijuana-related scientific research results have not been well considered in the policy making process. When people subconsciously indulge in something that is already notorious, they avoid it and overemphasize what seems good, while using illogical analogies to obliterate the disadvantages. We herein will objectively review the potential short- and long-term effects of marijuana, so as to sound the alarm for the legal use of marijuana.

\section{KEYWORDS}

Marijuana; Cognition Distortion; Memory Impairment; Intelligence Decline; Addition Potential

Sci Insigt. 2020; 32(3):133-137. doi:10.15354/si.20.re051.

\footnotetext{
Author Affiliations: Author affiliations are listed at the end of this article.

Correspondence to: Dr. Johnson S. Leonard, Ph.D., Division of Medicine and Public Health, The Bonoi Academy of Science and Education, Chapel Hill, NC 27510, USA

Email: jsleonard@basehq.org
} 
$\mathrm{R}$ EGARDING abused drugs, few people discuss the effects of drugs on a person's physical function and mental state (1). Regarding marijuana, some people say that the addiction is not as high as cigarettes, and the harm (social hazard + treatment cost) is not as bad as cigarettes, so they are very concerned about the ban on marijuana. Usually, not everyone is a pharmacologist or neuroscientist, so it is rare to discuss the effects of marijuana on the brain.

\section{SHORT-TERM EFFECTS OF MARIJUANA}

\section{Emotional Cognitive Distortion}

Yes, marijuana makes people feel very high, which is partially correct. Most of the time, smoking marijuana creates a feeling of joy, happiness, and refreshment, but this is occasional (2). Marijuana also makes people feel anxious and feels that something bad is going to happen (3). Why?

One effect of marijuana is to improve sensory sensitivity (4). It is not that people are more sensitive on the direct senses. Instead, it stimulates the thalamus to amplify some of the sensory signals received, while blocking out some pain signals (5).

Most people smoke marijuana at the party where the environment is generally pleasant and marijuana will magnify the pleasure effect. Even some not-soridiculous thoughts and ideas can produce a giggle response, because marijuana magnifies the response to positive information. However, in some cases, such as a person taking marijuana quietly, it has a calming effect and can sometimes relieve pain (6). Therefore, the effect of marijuana is closely related to the environment, mainly because it affects the perception function of the brain.

\section{Time Cognitive Distortion}

Marijuana makes people feel that time is passing more slowly (7). For example, after listening to a short paragraph for one minute, he felt that he had been raging for 30 minutes, and then he smirked secretly, thinking, "What are you talking about for such a long time?" This is mainly because marijuana causes a decrease in blood supply to the cerebellum, which is related to people's perception of time.

\section{Short-Term Memory and Cognitive Decline}

Marijuana can significantly affect short-term memory (8). When marijuana works, it's very easy for people to get distracted, in other words, they lose the ability to maintain attention and organize information. When you ask a person who uses marijuana, you will find that he / she is often unwilling, rolls his eyes at your questions, and often asks you repeatedly "What did you just say?", "Ah, what?", "You say it again?" and so on. Then it was his/her turn to say something, and he/she forgot what he/she should say, and "suddenly forgot everything."

This phenomenon is very similar to Korsakoff's psychosis (syndrome), which is also caused by chronic alcoholism (9). Korsakoff syndrome is mainly caused by alcohol damage in the hippocampus of the human brain's memory hub, resulting in short-term memory loss. And marijuana also affects the function of the hippocampal gyrus, causing short-term memory capacity to decline, making it very difficult for people to focus, to respond to others' thoughts, and to produce complete sentences and thoughts. That is to say: after taking marijuana, IQ drops sharply (10).

\section{LONG-TERM EFFECTS OF MARIJUANA}

Why is it difficult to get rid of drug addiction? Due to excessive doses of neuropharmaceuticals, they will temporarily replace human's natural nervous system. If you take the drug for a long time, part of the nerve function will no longer operate autonomously because of the excessive impact of the drug, and will need to be driven by drugs from now on (11). In other words, any neurologic drug will more or less change the original neural structure, and the changes caused by some drugs are irreversible. Even if it is reversible, the drug will be stopped when recovering, which is worse for some drug users. At this moment, the drug abuser is no longer a normal person.

What are the long-term effects of marijuana? This is a contentious topic. Of course, the controversy is mainly caused by misreading of scientific research by the media, selective release by a small group of people with ulterior motives, and public ignorance. There is still a lot of consensus in the scientific community.

Increase Offensive and Violent Crime? No. 
Because of its calming effect, marijuana is directly related to reducing aggression (12). There are some extreme cases, but majorly because the abuser has other mental problems.

\section{Cause Schizophrenia? Not Quite Right.}

Overdose of marijuana, especially tetrahydrocannabinol (THC), can lead to extreme anxiety and panic, feeling that you are out of reality and going crazy. This is mainly because of overdose caused complex hallucinations, loss of some sensory functions, and confusion of sensory functions. However, this short-term panic can be naturally relieved, that is, it can be left in a quiet environment for a while. In more severe cases, sedative drugs are needed.

This short-term schizophrenia led early researchers to believe that the use of marijuana can lead to schizophrenia (13). But new research suggests that sooner or later, these schizophrenics will do so, and marijuana simply accelerates their illness. Marijuana alone cannot cause schizophrenia $(14,15)$.

\section{Impact on Long-Term Intelligence? It's True.}

The abusers of marijuana will get a low IQ in a short period of time, but after about one month, if the marijuana is consumed only once, the effect of reducing IQ will disappear. Some long-term studies have shown that even for vulnerable adolescents, the effects of declining IQ can be restored in the long term (16).

At present, although it is impossible to prove cause and effect in a scientific way, those who use marijuana for a long time will be more numb and lazy than ordinary people. Marijuana has an influence on the stimulation mechanism inside the human brain, which will affect the secretion of dopamine and GABA (11). However, it is difficult to prove that these personality traits are causally related to marijuana ingestion and whether there is permanent damage. Because of smoking marijuana, the person may have certain personality problems. Therefore, it can only prove relevant, but not the cause and effect.

But smoking marijuana does have a significant impact on the social success of smokers (17). Compared with non-marijuana smokers, marijuana smokers have worse social and academic achievements, and the sooner they smoke, the worse the condition. Of course, this does not prove a causal relationship between marijuana and low IQ because people who abuse marijuana may have low discipline, parents are not disciplined, or they are engaged in specific occupations and careers, which may cause social achievements and Academic achievement is not high.

Intelligence is not a purely natural thing. Just as you do not know how tall a tree is by nature, you can't know how smart a person is by nature. Because all trees need water, nutrients, and sunlight to grow, so a sapling with the best genetics is a rotten seed without material nourishment. The same is true of intelligence. A child is inherently intelligent, without learning knowledge, without systematic training, and without continuously exercising his own thinking. As the age of the brain increases, the rate of brain cell death is faster than the rate of new life.

Marijuana will reduce IQ in a short time, make you fall behind, make you lose opportunities, make you lose trust, make you lose image. We all know that opportunities for development are actually extremely valuable to a person. When you were the youngest and most energetic, you were dragged down by your own low IQ and lost a few opportunities. Then, your life is naturally falling behind, and your future is naturally dim. This more or less reflects the "Butterfly Effect" caused by abusing marijuana.

\section{Reproductive Effects}

Marijuana increases sexual desire in men and women, but with increasing doses it causes impotence in men. For women, sexual pleasure is increased because it makes them more sensitive (18).

Unlike cigarettes, pregnant women taking marijuana do not have significantly lower body weight than normal, but marijuana seems to have a certain effect on the cognitive function of the newborn (19). For example, pregnant women taking marijuana during pregnancy have irregular sleep patterns before the age of three. Studies have also shown that taking marijuana during pregnancy is associated with ADHD, impulsivity, and learning disabilities in children (20-22).

\section{Immune System and Cancer}

The research uncertainty here is relatively large, and no conclusion has yet been determined. But marijuana af- 
fects the immune system, mainly on white blood cells and some inflammations (23). But the impact is very complex, and no conclusion has been determined at this time. There is evidence that smoking and marijuana at the same time can accelerate the incidence of lung cancer (24). But controversial evidence exists regarding marijuana's role in causing or mitigating DNA damage (25, 26). Therefore, the relationship between marijuana and cancer is uncertain.

\section{Trigger Other Drug Abuse}

It is true that almost all heroin users have smoked marijuana, but this does not prove that marijuana smoking will lead to heroin use (27). First, the pharmacological mechanisms of the two are different; second, chronological relationships do not represent causality. Almost all drinkers have drunk water before, and it cannot be said that drinking water leads to drinking alcohol. Heroin consumption is more of other social and environmental factors. For example, if you enter the circle of smoking marijuana, you may be tempted by your friends to use other drugs, and your self-control ability was poor at this time, but this is mainly caused by bad friends, and has little to do with the physiological effects caused by marijuana.

\section{MARIJUANA ADDICTION}

Marijuana is somewhat addictive but relatively low compared to other drugs (11). Withdrawal reactions generally occur when you stop taking 1-3 days: cravings for marijuana, changes in appetite, and restlessness, etc. The symptoms can last 4 to 14 days (28). From the point of view of withdrawal, marijuana's addiction is relatively low, but it can still cause addiction (29).

\section{CONCLUDING REMARKS}

In the short term, marijuana will increase human sensory sensitivity. It creates happiness most of the time and sometimes anxiety. There is also a certain sedative effect. But the cost is that IQ decreases over time and time perception is distorted. In the long run, it is currently impossible to prove that marijuana has a significant longterm harm to humans, but this does not mean that it does not. It can only be seen from the mechanism that it has an impact on the immune system and the cognitive system, but the long-term effect is uncertain. There is a butterfly effect due to short-term IQ decline. Marijuana's withdrawal response is not that severe, and the cost of withdrawal is lower than other drugs, but it is there, so we need to consider all these seriously.

\section{ARTICLE INFORMATION}

Author Affiliations: Division of Medicine and Public Health (Leonard), and Division of Neuroscience (Pathak), The Bonoi Academy of Science and Education, Chapel Hill, NC 27510, USA

Author Contributions: Dr. Leonard has full access to all of the data in the study and takes responsibility for the integrity of the data and the accuracy of the data analysis.

Study concept and design: Leonard and Pathak. Acquisition, analysis, or interpretation of data: Leonard and Pathak.
Drafting of the manuscript: Leonard and Pathak.

Critical revision of the manuscript for important intellectual content: Leonard and Pathak.

Statistical analysis: N/A.

Obtained funding: N/A.

Administrative, technical, or material support: Leonard and Pathak.

Study supervision: Leonard.

Conflict of Interest Disclosures: Leonard and Pathak declared no competing interests of this manuscript submitted for publication.
Funding/Support: N/A.

Role of the Funder/Sponsor: N/A.

How to Cite This Paper: Leonard JS, Pathak MK. Legal use of marijuana: will scientific evidence overwhelm self-perceived high feeling? Sci Insigt. 2020; 32(3):133-137.

Digital Object Identifier (DOI): http://dx.doi.org/ 10.15354/si.20.re051.

Article Submission Information: Received, January 11, 2020; Revised: January 29, 2020; Accepted: February 10, 2020.

\section{REFERENCES}

1. Leonard JS, Pathak MK, Wang F. Marijuana and brain: The debating Focus of science and economy. Sci Insigt 2015; 13(3):501-508.
2. Lukas SE, Mendelson JH, Benedikt R. Electroencephalographic correlates of marihuana-induced euphoria. Drug
Alcohol Depend 1995; 37(2):131-140.

3. Grunberg VA, Cordova KA, Bidwell LC, Ito TA. Can marijuana make it 
better? Prospective effects of marijuana and temperament on risk for anxiety and depression. Psychol Addict Behav 2015; 29(3):590-602.

4. Mikulskaya E, Martin FH. Contrast sensitivity and motion discrimination in cannabis users. Psychopharmacology (Berl) 2018; 235(8):2459-2469.

5. Vukadinovic Z, Herman MS, Rosenzweig I. Cannabis, psychosis and the thalamus: a theoretical review. Neurosci Biobehav Rev 2013; 37(4):658-667.

6. Temple LM. Medical marijuana and pain management. Dis Mon 2016; 62(9):346-352.

7. Hadley W, Barker D, Thamotharan S, Houck CD. Relationship between unsupervised time and participation in an emotion regulation intervention and risk outcomes. J Dev Behav Pediatr 2017; 38(9):714-722.

8. Busquets-Garcia A, Gomis-González M, Salgado-Mendialdúa V, GaleraLópez L, Puighermanal E, MartínGarcía E, Maldonado R, Ozaita A. Hippocampal protein kinase $\mathrm{C}$ signaling mediates the short-term memory impairment induced by delta9tetrahydrocannabinol. Neuropsychopharmacology 2018; 43(5):1021-1031.

9. Bruijnen CJWH, Dijkstra BAG, Walvoort SJW, Markus W, VanDerNagel JEL, Kessels RPC, DE Jong CAJ. Prevalence of cognitive impairment in patients with substance use disorder. Drug Alcohol Rev 2019; 38(4):435-442.

10. Wilkinson ST, Radhakrishnan R, D'Souza DC. A systematic review of the evidence for medical marijuana in psychiatric indications. J Clin Psychiatry 2016; 77(8):1050-1064.

11. Zehra A, Burns J, Liu CK, Manza P, Wiers CE, Volkow ND, Wang GJ. Cannabis addiction and the brain: $A$ review. J Neuroimmune Pharmacol 2018; 13(4):438-452.

12. Savage RJ, King VL, Clark CB, Cropsey KL. Factors associated with early marijuana initiation in a criminal justice population. Addict Behav 2017; 64:82-88.

13. Fischer BA, McMahon RP, Kelly DL, Wehring HJ, Meyer WA, Feldman S, Carpenter WT, Gorelick DA. Risktaking in schizophrenia and controls with and without cannabis dependence. Schizophr Res 2015; 161(23):471-477.

14. Ortiz-Medina MB, Perea M, Torales J, Ventriglio A, Vitrani G, Aguilar L, Roncero C. Cannabis consumption and psychosis or schizophrenia development. Int J Soc Psychiatry 2018; 64(7):690-704.

15. Hamilton I. Cannabis, psychosis and schizophrenia: Unravelling a complex interaction. Addiction 2017; 112(9):1653-1657.

16. Jager G, Kahn RS, Van Den Brink W, Van Ree JM, Ramsey NF. Long-term effects of frequent cannabis use on working memory and attention: an fMRI study. Psychopharmacology (Berl) 2006; 185(3):358-368.

17. Andrade C. Cannabis and neuropsychiatry, 1: Benefits and risks. J Clin Psychiatry 2016; 77(5):e551-e554.

18. Palamar JJ, Griffin-Tomas M, Acosta P, Ompad DC, Cleland CM. A comparison of self-reported sexual effects of alcohol, marijuana, and ecstasy in a sample of young adult nightlife attendees. Psychol Sex 2018; 9(1):5468.

19. Silva L, Zhao N, Popp S, DowEdwards D. Prenatal tetrahydrocannabinol (THC) alters cognitive function and amphetamine response from weaning to adulthood in the rat. Neurotoxicol Teratol 2012; 34(1):63-71.

20. Elkins IJ, Saunders GRB, Malone SM, Keyes MA, McGue M, lacono WG. Associations between childhood ADHD, gender, and adolescent alcohol and marijuana involvement: A causally informative design. Drug Alcohol Depend 2018; 184:33-41.

21. Haas AL, Zamboanga BL, Bersamin M, Hyke T. Perceived access and parental monitoring as moderators of impulsivity and marijuana use among adolescents. J Prim Prev 2018; 39(2):155-169.

22. Nestor L, Roberts G, Garavan H, Hester R. Deficits in learning and memory: Parahippocampal hyperactivity and frontocortical hypoactivity in cannabis users. Neuroimage 2008; 40(3):1328-1339.

23. Dong C, Chen J, Harrington A, Vinod KY, Hegde ML, Hegde VL. Cannabinoid exposure during pregnancy and its impact on immune function. Cell Mol Life Sci 2019; 76(4):729-743.

24. Sherman MP, Aeberhard EE, Wong VZ, Simmons MS, Roth MD, Tashkin DP. Effects of smoking marijuana, tobacco or cocaine alone or in combination on DNA damage in human alveolar macrophages. Life Sci 1995; 56(23-24):2201-2207.

25. Lowe HI, Toyang NJ, McLaughlin W. Potential of cannabidiol for the treatment of viral hepatitis.

Pharmacognosy Res 2017; 9(1):116118.

26. Russo C, Ferk F, Mišík M, Ropek N, Nersesyan A, Mejri D, Holzmann K, Lavorgna M, Isidori M, Knasmüller S. Low doses of widely consumed cannabinoids (cannabidiol and cannabidivarin) cause DNA damage and chromosomal aberrations in human-derived cells. Arch Toxicol 2019; 93(1):179-188.

27. Hurd YL, Spriggs S, Alishayev J, Winkel G, Gurgov K, Kudrich C, Oprescu AM, Salsitz E. Cannabidiol for the reduction of cue-induced craving and anxiety in drug-abstinent individuals with heroin use disorder: $A$ double-blind randomized placebocontrolled trial. Am J Psychiatry 2019; 176(11):911-922.

28. Grotenhermen F. Pharmacokinetics and pharmacodynamics of cannabinoids. Clin Pharmacokinet 2003; 42(4):327-360.

29. Bonnet U, Preuss UW. The cannabis withdrawal syndrome: current insights. Subst Abuse Rehabil 2017; 8:9-37. 